\title{
RELEVÂNCIA DA CRIMINOLOGIA NA RESOLUÇÃO DE CASOS DE FEMINICÍDIO NO MUNIÍCIPIO DE REDENÇÃO-PA
}

\author{
Elainy Brandão Silva ${ }^{1}$ \\ Francinete Pereira da Silva Santos ${ }^{2}$ \\ Lara Vitória da Silva Soares ${ }^{3}$ \\ Otávio Augusto Fernandes Mascarenhas França ${ }^{4}$ \\ Thainara da Silva Siqueira ${ }^{5}$
}

RESUMO: O artigo em questão objetiva, mostrar a relevância da criminologia nos crimes de feminicídios, haja vista que esses crimes são praticados contra mulheres e virtude do seu gênero. Devido a grande necessidade de se punir os culpados que praticam tal delito, esse crime foi introduzido no ordenamento jurídico pela lei 13.104/2015 que visa proteger a vida, em especial no que concerne a vida das mulheres. O objetivo maior do referido artigo é ampliar o conhecimento sobre essa temática, levando a sociedade a refletir sobre o feminicídio e como esse crime tem sido tratado pelo ordenamento jurídico. Para maior embasamento, foi realizada uma pesquisa bibliográfica e de campo referenciando diversos autores que tratam sobre o tema, trata-se de uma pesquisa com abordagem qualitativa de revisão bibliográfica através do método dedutivo, atingindo o público alvo de estudantes e demais autores sociais que desejam aprofundar sobre o tema.

Palavras-chave: Feminicídio. Gênero . Crime. Vida.

ABSTRACT: The article in question aims to show the relevance of criminology in feminicide crimes, given that these crimes are committed against women and due to their gender. Due to the great need to punish the guilty who commit such a crime, this crime was introduced into the legal system by law $13.104 / 2015$, which aims to protect the greater good that is life, especially with regard to women's lives. The main objective of this article is to expand knowledge on this topic, leading society to reflect on femicide and how this crime has been treated by the legal system. For greater support, a bibliographical and field research was carried out, referencing several authors who deal with the subject. delve into the topic.

Keywords: Femicide. Genre . Crime. Life.

\footnotetext{
'Acadêmica de Direito Fesar-Afya

${ }^{2}$ Graduada em Letras-UFPA

${ }^{3}$ Acadêmica de Direito Fesar-Afya

${ }^{4}$ Acadêmico de Direito Fesar-Afya

${ }^{5}$ Acadêmica de Direito Fesar-Afya
} 


\section{INTRODUÇÃO}

O feminicídio diz respeito ao crime de homicídio praticado contra a mulher, em decorrência do seu gênero. A Lei do Feminicídio surgiu em decorrência dos altos índices apresentados de crimes praticados contra mulheres no Brasil. São diversos os tipos de feminicídio os quais serão abordados no decorrer deste estudo. Haja vista, que esse tipo de crime tem sido uma prática que tem levado muitas mulheres a perderem suas preciosas vidas em detrimento do gênero sexual.

A busca pelo aprimoramento e entendimento do tema ocorreu em detrimento da extrema preocupação em apreender quais as providencias tem sido adotada a esse respeito, como também perceber em que medida a criminologia tem contribuído para amenizar essa situação devastadora contra as mulheres.

Partindo dessa premissa, é necessário entendermos o conceito de criminologia como também compreender o conceito de feminicídio para uma maior abordagem sobre o tema. Ao analisar com mais precisão, pode-se entender que a criminologia é uma ciência que estuda os fenômenos a respeito do crime, buscando entender o que levou o ser humano a praticar o delito, assim percebe-se que a criminologia é de suma relevância para esclarecer as práticas dos delitos no meio social, e como esse índice tem se desenvolvido na atualidade.

Pode-se afirmar que o feminicídio, é um crime que está descrito no Código Penal brasileiro, onde o prever como circunstância qualificadora do crime de homicídio (art. I2I), tendo sido inserido neste rol por meio da Lei. 13.104/2015, coligada à Lei Maria da Penha (Ir.340/2006), e o art. Io da Lei no 8.072/199o, incluiu o feminicídio no rol dos crimes hediondos. Logo, as leis em consonância procuram evitar, minimizar e principalmente penalizar os crimes contra mulher, assegurando-as, na luta contra a discriminação e o preconceito. Vale ressaltar, que a maioria desses delitos são cometidos pela simples condição da mulher pertencer ao sexo feminino, ou seja, torna-se uma vítima em razão do seu gênero.

Para Prado a mulher tende a ser vista como um gênero fraco e vulnerável, porém diferente do que é visto por muitos ela tem um grandioso significado, sendo na verdade um ser amável na sociedade (PRADO, 2019). De acordo com o autor é possível verificar que 
tem sido uma situação constrangedora para as mulheres, que por se encontrar em situação vulnerável perdem suas vidas, simplesmente pelo fato de serem mulheres.

Deste modo, por entender que esse tema é de suma relevância para a sociedade, e que esse impasse tem se desenvolvido de maneira constante no meio social, houve o interesse por entender qual a relevância da criminologia na resolução dos casos de feminicídios no município de Redenção-Pará, e quais providências têm sido tomada para resolver e prevenir esses problemas sociais.

Sobre o proposto tema, tal estudo visa realizar a análise da relevância da criminologia na resolução de casos de feminicídio no munícipio de Redenção-PA, onde o mesmo irá partir da análise e do estudo da ciência da criminologia nos seus mais variados aspectos, trazendo como ponto principal sua magnitude no que diz respeito ao feminicídio juntamente com a lei 13.104/2015, que incluiu a qualificadora do feminicídio ao artigo I2I, § 2º inciso VI, do Código Penal (CP) no rol dos homicídios qualificados, a qual possuí o nome de Lei do Feminicídio.

\section{I-A ORIGEM DO TERMO FEMINICÍDIO}

$\mathrm{Na}$ atualidade muito se tem discutido sobre o feminicídio, dados estatísticos afirmam que mesmo sobrevivendo aos riscos do coronavírus, diversas mulheres vieram a óbito em consequência de violência doméstica. A pandemia que assolou o mundo agravou ainda mais tal crime. Todavia vale ressaltar que a mesma existe desde os primórdios, vinculada a um racismo estrutural. O renomado jurista e especialista em Direito Penal brasileiro Damásio de Jesus, dispõe em seu livro que:

\footnotetext{
A violência é, cada vez mais, um fenômeno social que atinge governos e populações, tanto global quanto localmente, no público e no privado, estando seu conceito em constante mutação, uma vez que várias atitudes e comportamentos passaram a ser considerados como formas de violência. (DAMÁSIO, 2006, p.7)
}

O termo feminicídio diz respeito, ao assassinato de uma mulher por questões de gênero; ou seja, quando a vítima é mulher e quando o crime envolver: violência doméstica e familiar ou menosprezo ou discriminação à condição de mulher. ele surgiu no ano de 1976 sendo a socióloga sul- africana Diana Russel a primeira pessoa a utilizar este termo, durante um 
simpósio realizado em Bruxelas, Bélgica. A mesma era componente do Tribunal Internacional de Crimes contra Mulheres. Sobre o feminicídio e sua relação com os fatores culturais pode-se afirmar que:

\begin{abstract}
O feminicídio é uma continuidade dessa tutela especial, considerando homicídio qualificado e hediondo a conduta de matar a mulher, valendo-se de sua condição de sexo feminino (vide tópico a seguir). "Radford definia o feminicídio como o assassinato de mulheres cometido por homens, como uma forma de violência sexual, aclarando que o conceito abarcava algo mais que a sua definição legal de assassinato, levando a situações nas quais as mulheres morrem como resultados de atitudes misóginas ou de práticas sociais. (NUCCI, 2021, p.40)
\end{abstract}

Diana vendo a necessidade de se haver um termo técnico que se especifica os homicídios praticados contra as mulheres, assegurou a ideia da criação de um, foi deste modo que surgiu o termo feminicídio. A violência contra mulher no Brasil também existe desde muito tempo historicamente falando, mas a palavra feminicídio só ganhou destaque no Brasil a partir de 2015, quando foi aprovada a Lei Federal 13.104/15.

Tal Lei é popularmente conhecida como a Lei do Feminicídio. Isso porque ela criminaliza o feminicídio, que é o assassinato de mulheres cometido em razão do gênero, ou seja, a vítima é morta por ser mulher, está lei foi criada com intuito também de eliminar às raízes discriminatória existente ainda em nossa sociedade. E também ressaltar a responsabilidade do Estado para tal cenário.

\title{
2-CONCEITO E FUNÇAO DA CRIMINOLOGIA
}

A palavra criminologia vem do latim crimino (crime) e do grego logos (estudo, tratado), significando o "estudo do crime". O termo "criminologia" foi usado pela primeira vez em 1883 por Paul Topinard e aplicado internacionalmente por Raffaele Garófalo, em seu livro Criminologia, no ano de 1885 . Raffaele Garófalo (1995, p. 36) definiu criminologia como a "ciência do delito", enquanto Hilário Veiga de Carvalho (1973, p. II) afirmou que a criminologia representa "o estudo do crime e do criminoso, isto é, da criminalidade".

A criminologia tem um conceito amplo, e além destes vários autores trouxeram seu entendimento sobre a matéria. Para Nelson Hungria (1963), "Criminologia é o estudo experimental do fenômeno crime, para pesquisar lhe a etiologia e tentar a sua debelação por 
meios preventivos ou curativos”. (FERNANDES; FERNANDES, 1995, p. 24). O Edwin H. Sutherland (1985) apresentou um importante conceito ao definir a criminologia como um conjunto de conhecimentos que objetivam estudar o fenômeno e as causas da criminalidade, a personalidade do criminoso, sua conduta delituosa e os meios de ressocializá-lo. E Antônio García-Pablos de Molina e Luiz Flávio Gomes (1999, p.39) apresenta uma definição bastante completa e aceita de criminologia ao conceituá-la como "ciência empírica e interdisciplinar, que se ocupa do estudo do crime, da pessoa do infrator, da vítima e do controle social do comportamento delitivo, e que trata de subministrar uma informação válida, contrastada, sobre a gênese, dinâmica e variáveis principais do crime - contemplado este como problema individual e como problema social, assim como sobre os programas de prevenção eficaz do mesmo e técnicas de intervenção positiva no homem delinquente".

Diante das diversas definições apresentadas, conclui-se que não há uma determinação predominante do conceito de criminologia. Mas, no entanto, pode-se concluir que a Criminologia trata-se, da ciência voltada ao estudo das causas do crime e das razões que levam alguém a delinquir, enfocando essas causas e razões por meio de métodos empíricos e pela observação dos fenômenos sociais, onde se insere a avaliação da vítima, apresentando críticas ao modelo punitivo existente e proporcionando sugestões de aperfeiçoamento da política criminal do Estado. O crime é um fenômeno social variável de tempos em tempos, o que poderia prejudicar a avaliação da criminologia como ciência. Assim não nos parece, visto que a base do delito se mantém inalterada desde os primórdios da humanidade, como a conduta mais lesiva a bens jurídicos tutelados, em certo lugar e em determinada época, merecedora da pena, dando ensejo a ser estudada em aspectos invariáveis e, pelo menos, frequentes e repetidos, possuindo o mínimo de estabilidade para se poder indicar ao direito penal as suas balizas. A meta da criminologia deve ser o aprimoramento do direito penal em todos os seus matizes.

Para SÉRGIO SALOMÃO SHECAIRA, o direito penal, a criminologia e a política criminal refletem os três alicerces sobre os quais se assentam as ciências criminais, formando um modelo integrado de ciência conjunta. Segundo nos parece, não considerando a política criminal como ciência criminal, mas um modo de raciocinar e estudar o direito penal, a fim 
de lhe dar a eficácia aguardada pelo Estado, nos termos da sua proposta de pacificação social, deve-se acrescentar nessa base o processo penal, que lida diretamente com a liberdade do indivíduo, desde o princípio da investigação criminal, podendo representar a privação antecipada de seu direito essencial de ir e vir, motivo pelo qual é preciso estudar, com maior zelo, essa força estatal prisional, embora de natureza cautelar. E o contexto ideal para isso se dá exatamente no cenário das ciências criminais, indagando-se sempre por que punir e quando punir.

É certo que deva a criminologia estudar o crime e o criminoso, mas o faz para avaliar a necessidade da aplicação da punição, levando a análise para as funções e as finalidades da pena, integrando o cenário global da infração penal e todas as suas consequências não só para o infrator, mas igualmente para a sociedade. Afinal, há uma cadeia de situações lógicas e sucessivas: prever como crime certa conduta, cominando-lhe uma pena; investigar, descobrir, processar e aplicar a sanção ao delinquente; e tornar efetiva a pena pelo seu cumprimento. Portanto, estão ligadas as causas do crime, as razões do seu autor, as penas aplicadas e a sua concretização. Esse é o universo do sistema punitivo, cujo estudo deve integrar as linhas da criminologia.

Dito isto, é possível compreender que a criminologia objetiva fornecer um diagnóstico qualificado do fenômeno criminal, ao estudar a criminalidade em todas suas causas. Por meio da investigação e análise experimental do crime, criminoso, vítima e do controle social, a criminologia possui condições de sugerir programas, diretrizes ou estratégias aos legisladores e poderes públicos, visando a prevenção, repressão do delito e ressocialização do delinquente numa perspectiva mais efetiva e com custos sociais adequados à população.

As principais funções modernas da Criminologia é explicar e prevenir o crime; intervir na pessoa do infrator; e avaliar os diferentes modelos de reposta ao crime (MOLINA; GOMES, 2007). Outra função principal da criminologia é encontrar meios para a prevenção de novos delitos, que perpassa não só pela implantação dos direitos sociais básicos (educação, saúde, trabalho, habitação, etc.), mas em atendimento a grupos vulneráveis que ostentam maior risco de sofrer com o problema criminal. Se não foi possível 
prevenir, encampa-se estudos no sentido de intervir positivamente na pessoa do infrator, buscando métodos eficazes de ressocialização, pois de antemão sabe-se que este delinquente retornará ao convívio social e é preciso reeducá-lo para que este não se perda e novamente volta ao mundo do crime.

No que tange a função de avaliar os diferentes modelos de reposta ao crime, atualmente, esta resposta não passa apenas pela punição e ressocialização do infrator, mas pela assistência das vítimas e de suas famílias na comunidade em que ocorreu o delito, visando restaurar todo círculo social afetado. A própria inovação da Lei nº. 11.340/o6 (Lei Maria da Penha) é reflexo de estudos criminológicos das mulheres vítimas de violência doméstica e familiar, que culminou na criação de mecanismos e diversas medidas de atendimento e assistência às vítimas, o que demonstra uma preocupação voltada em atingir todos os níveis, desde a prevenção, punição e erradicação da violência contra a mulher na sociedade

Os autores modernos, copiosamente, escrevem que a "função linear da Criminologia é informar a sociedade e os poderes públicos sobre o crime, o criminoso, a vítima e o controle

social, reunindo um núcleo de conhecimentos seguros que permita compreender cientificamente o problema criminal, preveni-lo e intervir com eficácia e de modo positivo no homem criminoso”. E assim, indicar um diagnóstico qualificado e conjuntural sobre o crime.

Diante das diferentes perspectivas, entende-se que a criminologia é uma ciência empírica e interdisciplinar que investiga e reflete sobre o ato de punir e o complexo fenômeno criminal ao estudar o crime, criminoso, vítima e controle social, visando subsidiar o legislador na criação/modificação das normas penais e os poderes públicos para agirem na prevenção, repressão do delito, ressocialização do criminoso e restauração do círculo social afetado.

\section{3-FEMINICIDIO A LUZ DA LEI MARIA DA PENHA}

A promulgação da Lei Maria da Penha exigiu tempo e esforço do movimento de mulheres do país, pois até a década de 1980, o Brasil não tinha instrumentos legais para 
proteger as mulheres da violência. Essa situação começou a mudar na década de I970, graças ao poderoso movimento de grupos de mulheres, que saíram às ruas com slogans "Quem ama, não mata", condenando a violência sofrida. Naquela época, eles começaram a dar o primeiro passo para a criação de novas prevenções a violência doméstica.

A criação dessa lei se deu pelo fato ocorrido em 1983, com a farmacêutica bioquímica brasileira Maria da Penha Fernández que foi severamente agredida pelo marido, professor da Universidade de Columbia. Ela foi vítima de duas tentativas de assassinato em sua família, primeiro, seu marido atirou nas costas dela enquanto ela dormia e como resultado, seu marido estava foragido e Maria ficou paralítica aos 38 anos. A segunda tentativa foi alguns meses depois, quando ele a empurrou para fora da cadeira de rodas enquanto tomava banho e tentou chocá-la com eletricidade. Ela só apresentou queixa sobre o caso ao Ministério de Relações Públicas no ano seguinte, e o primeiro julgamento por esses crimes ocorreu somente oito anos depois, seu advogado conseguiu cancelar o primeiro julgamento e, em 1996, ele foi considerado culpado e condenado a dez anos de prisão. No entanto, ele conseguiu apelar da decisão e 15 anos após o crime ter sido cometido por ineficácia do sistema judiciário brasileiro, o caso ainda era inconclusivo.

O homicídio de mulheres em razão de sua condição feminina é tido como a lei do feminicídio o proposito desta distinção é que em nossa sociedade patriarcal, as mulheres ainda sofrem frequentemente com relacionamentos abusivos, violência doméstica e tratamento degradante e desumano por serem mulheres, sendo comum a violência e homicídio com tais características, a lei que prever tal crime é a 13.104/2015.

Contudo a Lei Maria da Penha está relacionada a prevenção, pois ela trouxe medidas protetivas que não havia ainda no código Penal, sendo sua eficácia ao impedir mortes anunciadas tendo em sua maneira proteção a vida da mulher quanto a ter uma diminuição desse tipo de crime, porém ela não trazia consigo a penalidade necessária para os agressores e assim foi feita a tipificação como sendo um crime hediondo a lei do feminicídio, pois a mesma tem caráter de penalidade para quem pratica tais atos contra mulheres. Portanto, ambas as leis mencionadas têm sua devida importância e colabora até 
hoje para nossa sociedade, sendo que uma complementa a outra, pelo fato de uma ter o papel de prevenir e a outra punir.

\section{4- A FUNÇÃO DO JUDICIÁRIO NA INVESTIGAÇÃO E PUNIÇÃO DO CRIME DE FEMINICÍDIO}

A violência contra a mulher tem sido um problema muito grave no meio social, tanto a violência doméstica, quanto o próprio feminicídio tem sido um grande agravante para as mulheres, visto que as mesmas necessitam de proteção contra os infratores, houve a necessidade da criação de leis que amparam as mesmas contra a violação dos direitos. Devido toda essa realidade desagradável que tem se perpetuado na sociedade houve a grande necessidade do estado ter uma atuação eficiente e eficaz no sentido prevenir, averiguar e castigar aqueles que praticam a violência de gênero.

$\mathrm{O}$ art. 129, VII, da Constituição Federal esclarece que uma das funções institucionais do Ministério Público é o controle externo da atividade policial. Sendo assim cabe ao ministério público assegurar a eficiência e fiscalizar as denúncias, tornando-se um círculo de colaboração entre polícia e ministério público, promovendo desta forma uma segurança pública mais eficiente no sentido de primar pela harmonia e paz social. Desta maneira podese entender que o ministério público tem a função de manter a preservação da ordem pública sendo incumbido dessa forma pela defesa da ordem jurídica em observância aos interesses da sociedade com referencia fiel a constituição e as leis vigentes.

Vale ressaltar o disposto no código penal em seu artigo I2I parágrafo $2^{\circ}$ e inciso VI que se o crime é praticado contra a mulher por razões da condição do sexo feminino a pena é de reclusão de doze a trinta anos. Percebe-se que foi acrescido esse inciso no código penal no intuito de punir os agentes que praticam tal delito em razão do gênero feminino. Isso mostra o quanto as mulheres sofreram com essa prática, sendo necessário a implantação de leis que possam resguardar a sua dignidade. Vale lembrar que o sujeito ativo normalmente costuma ser um homem, porém poderá ser cometido também por uma mulher.

Nesse formato, deverão ser levados em consideração a atuação do estado na proteção da violência doméstica e familiar, com observância sempre na lei Lei no II.340, de 2006, este 
tem o dever de procurar manter a eficiência, buscando manter e resguardar o direito fundamental, sendo este a preservação da integridade física, emocional e moral das mulheres, cabendo ao ministério público como órgão de controle a essa atividade fiscalizar e garantir que não haja violação de direitos.

Portanto, pode-se dizer com base na Constituição Federal de $1988 \mathrm{em}$ seu artigo $5^{\text {a }}$ que trata sobre os direitos fundamentais que todos temos direito a vida, a liberdade, a segurança e a propriedade, sendo esses entre outros bens fundamentais. Entre todos esses direitos fundamentais está a segurança que está cunhada no artigo $6^{\circ}$ da CF como sendo um direito e responsabilidade do estado proporcionar tal segurança para os cidadãos. Deste modo pode-se afirmar que é responsabilidade do estado através dos órgãos competentes a preservação da ordem pública, ficando dentro de rol de responsabilidade a integridade da mulher sendo essa um personagem fundamental para a sociedade

\section{5- DADOS GERAIS DA VIOLÊNCIA CONTRA MULHER EM REDENÇÃO-PA}

A pesquisa de campo tem como objetivo entender e analisar a prática do feminicídio

em Redenção, trata-se de um município brasileiro situado no estado do Pará, sendo destaque entre outros estados no que tange as suas riquezas e belezas naturais.

A economia do município de Redenção é baseada na pecuária que fornece gado para vários frigoríficos a nível nacional e internacional, incluindo em seu rol de riquezas o plantio de soja que vem sendo um atrativo para os que desejam ingressar no mercado consumidor. $\mathrm{Na}$ qualidade de estudante do curso de direito e de futuros advogados no qual será necessário desenvolver tarefas essenciais para a administração da justiça, a busca de resposta pelo tema citado tornou-se, de grande relevância, por entender que a mulher merece ser respeitada e amada por todos do meio social, com seus direitos e deveres observado por todos.

Ao falar em feminicídio é válido ressaltar o seu conceito com observância ao código penal Brasileiro e demais legislações vigentes, assim, pode-se afirmar que feminicídio é o homicídio doloso cometido contra a mulher sendo esse homicídio praticado em detrimento da condição de sexo feminino", ou seja, o crime acontece simplesmente pela razão do gênero, 
violando e desprezando a dignidade do ser mais afável, em virtude desta, ser considerada menos capaz pelo fato de unicamente ser uma mulher.

Mediante ao exposto vale lembrar que o feminicídio é um crime doloso, o código penal em seu art. I2I trata sobre as modalidades desse crime, estipulando uma pena de doze a trinta anos, se o homicídio ocorrer contra uma mulher em detrimento da condição de mulher, vindo reforçar e assegurar os direitos da mulher a Lei da Maria da Penha lei $\mathrm{n}^{\circ}{ }^{11.340 / 2006}$, surge como uma segurança para todas as mulheres que não se calam e procuram a justiça para denunciar os abusos e agressões sofridos.

Em observância ao site da delegacia da mulher pode-se constar por meio de reportagem fidedigna que os números de violências contra as mulheres não param de crescer, sendo assim, um grande prejuízo para a dignidade das heroínas que lutam a cada dia pela sua sobrevivência em meio uma sociedade violenta e sanguinária. Segundo a reportagem a violência doméstica entre os meses de março e abril do ano de 2020 , durante a pandemia do novo coronavírus, apontou que os casos de feminicídio no país aumentaram em $5 \%$ em relação ao período de 2019, sendo o Mato Grosso o Estado que mais praticou tal ato ilícito contra a dignidade da mulher no período da pandemia.

Em Redenção-Pará a falta de transparência nas informações gera um grande desconforto para os que necessitam se aprofundar nos estudos e pesquisas sobre a prática do feminicídio neste munícipio, são dados vagos e imprecisos que constam nos autos da polícia militar, poucos são os registros de casos sobre feminicídio. Em pesquisa ao site da Policia Civil, constatou-se, três crimes de violência contra mulher. Sendo os mesmos tidos como tentativa de feminicídio, com graves lesões corporais. A falta de transparência nas informações se concretiza pelo amplo conhecimento de violência contra a mulher no município, ficando esses crimes impunes e não declarados nos bancos de dados do judiciário de Redenção. Quanto ao motivo dessa falta de informação, podemos apontar alguns fatores como; medo, insegurança e dependência da mulher, para que aconteça o silêncio e a retirada de queixa do agressor.

Uma prova de falta de informações são os 73 procedimentos policiais feito contra violência doméstica em Redenção no ano de 2019, em uma campanha alusiva ao mês da 
mulher, trata-se de procedimentos entre inquéritos, Autos de Infração e Boletins de Ocorrência Circunstanciados (BOCs), pela equipe coordenada pela delegada Maria de Fátima Chaves dos Santos em Redenção, provando desse modo ser Redenção uma cidade que possui hábitos e práticas de violências contra mulher. Mediante ao apontado, torna-se de grande importância uma política de conscientização que possa gerar segurança e tranquilidade para as vítimas de agressões e familiares que tiveram casos de feminicídios em suas famílias se calando pelo medo, angustia e insegurança, temendo pela vida.

\section{CONCLUSÃO}

Destarte como vimos no decorrer deste trabalho a violência contra as mulheres tem sido algo recorrente no meio social, se repercutindo desde os primórdios até os dias atuais, o lar onde deveria ser um lugar de paz e amor, muitas das vezes tem se transformado em um ambiente de castigo e opressão para as afáveis mulheres. É válido afirmar, que o surgimento das leis de proteção da integridade física, emocional e moral da mulher tem sido um divisor de águas no meio social. A mulher passa desta forma, a ser mais valorizada e respeitada, com um auxílio de um amparo legal da legislação para punir os violadores desse direito.

A tipificação do crime de feminicídio no ordenamento jurídico, foi muito importante para garantir os direitos das mulheres, como também foi crucial para mostrar a verdadeira máscara social, onde diversas mulheres são agredidas e mortas pelo simples fato de pertencer ao gênero feminino, isso mostra de alguma forma que ainda vivenciamos em uma sociedade machista, onde as marcas de agressões estão estampadas no corpo e na mente das mulheres, que muitas das vezes sofrem caladas temendo pelo bem precioso que é a vida.

No entanto jamais pode-se negar que a legislação cumpre seu papel de proteção a vida, considerando que a mulher necessita de amparo e proteção contra os agressores, sendo estes punidos de acordo com a lei de proteção aos direitos da mulher. Vale destacar que há algumas diferenças importantes nas legislações que tende a primar pela proteção da mulher, onde a lei Maria da Penha visa proteger a mulher contra as agressões físicas, sendo estas praticadas no âmbito familiar, enquanto a lei do feminicídio, visa aplicar penas mais severas 
contra os agentes que cometem homicídio contra as mulheres em detrimento do gênero feminino.

Assim, pode-se concluir que o judiciário tem agido com muita cautela e preocupação quanto a esse tipo de crime, sendo notório isso no agravante do aumento de pena para quem pratica tal crime, porém o que se percebe-se, é que muitas mulheres ainda continuam sendo agredidas e perdendo suas vidas. Partindo desse princípio, há que se pensar em outros fatores, para que essa prática termine e as mulheres possam ser tratadas com o respeito e dignidade que tanto merecem.

\section{REFERÊNCIA}

BRASIL. Constituição (1988). Constituição da República Federativa do Brasil. Disponível em: 〈http://www.planalto.gov.br/ccivil_03/constituicao/ConstituicaoCompilado.htm> acesso em novembro. 2021.

BRASIL. LEI MARIA DA PENHA. Lei N. ${ }^{\circ}$ II.340, de 7 de Agosto de 2006

BRASIL. LEI DO FEMINICÍDO. LEI № 13.104, DE 9 DE MARÇO DE 2015. GOMES, Marcos.Vinicius.Manso. L.; MAIA, Erick. F. Coleção Defensoria Pública - Ponto a Ponto - Execução Penal Criminologia. [Digite o Local da Editora]: Editora Saraiva, 202I. 9786555598476 .

em: https://integrada.minhabiblioteca.com.br/\#/books/9786555598476/. Acesso em: 04 nov. 2021.

NUCCI, Guilherme de Souza. Criminologia. [Digite o Local da Editora]: Grupo GEN, 202I. 9786559641437. Disponível

em: https://integrada.minhabiblioteca.com.br/\#/books/978655964I437/. Acesso em: 04 nov. 202I.

JESUS, Damásio. D. Violência contra a mulher : aspectos criminais da Lei $n$. $11.340 / 2006,2^{\underline{a}}$ edição.. [Digite o Local da Editora]: Editora Saraiva, 2014. 9788502616028. Disponível em: https://integrada.minhabiblioteca.com.br/\#/books/9788502616028/. Acesso em: 04 nov. 2021. 
SOUZA, NUCCI,.Guilherme. D. Curso de Direito Penal - Parte Especial - Vol. 2. [Digite o Local da Editora]: Grupo GEN, 2021. 9786559640157. Disponível em: https://integrada.minhabiblioteca.com.br/\#/books/9786559640157/. Acesso em: o4 nov. 202I. 